\title{
Walnut Meal Whitening and the Impact of Whitening Factors on Its Quality
}

\author{
Grosu Carolina1,2, Siminiuc Rodica1,2*, Dinu Turcanu ${ }^{2,3}$, Covaliov Eugenia1,2, Gutium Olga ${ }^{1,2}$ \\ ${ }^{1}$ Food and Nutrition Department, Technical University of Moldova, Chisinau, Republic of Moldova \\ ${ }^{2}$ Technical University of Moldova, Chisinau, Republic of Moldova \\ ${ }^{3}$ Informatization, Partnerships, Institutional Image and Communication Office, Chisinau, Republic of Moldova \\ Email: `rodica.siminiuc@adm.utm.md, dinu.turcanu@adm.utm.md, carolina.grosu@cdmp.utm.md, \\ eugenia.boaghi@toap.utm.md, olga.gutium@toap.utm.md
}

How to cite this paper: Carolina, G., Rodica, S., Turcanu, D., Eugenia, C. and Olga, G. (2021) Walnut Meal Whitening and the Impact of Whitening Factors on Its Quality. Food and Nutrition Sciences, 12, 1-12. https://doi.org/10.4236/fns.2021.121001

Received: December 4, 2020

Accepted: January 15, 2021

Published: January 18, 2021

Copyright $\odot 2021$ by author(s) and Scientific Research Publishing Inc. This work is licensed under the Creative Commons Attribution International License (CC BY 4.0).

http://creativecommons.org/licenses/by/4.0/

\begin{abstract}
Walnut meal is a nutrient-rich product and has a high nutritional value. Walnut meal is a product that can be used in food technology, in order to improve the nutritional quality, expand the range of confectionery products, and replaces the walnut kernel. Due to the dark color, the use of the walnut meal in the preparation of pastries would have a negative effect on the appearance of some final products and the whitening process would allow its use without negatively influencing the final product. The aim of the research is to whiten Juglans regial $L$. walnut meal as a valuable nutritious raw material. Hydrogen peroxide was used to bleach the walnut meal, and the $\mathrm{pH}$, concentration of the whitening agent and the concentration of the meal were used as variable parameters of the bleaching process. The color descriptors (Whitening index, Saturation index, Total color difference, Browning index) were calculated to establish the optimal whitening conditions of the walnut meal. The obtained results showed that an alkaline medium, with the hydrogen peroxide concentration of $10 \%$ and $2.5 \%$ meal concentration allows obtaining the best color parameters in terms of Lightness (82.20) and Whitening Index (71.20). In addition, the study of walnut meal quality in terms of peroxide value evolution showed that the treatment with hydrogen peroxide does not affect in any way the value of the peroxide index of the lipids. The highest peroxide value $(4.91 \mathrm{mmol} / \mathrm{g}$ oil) was recorded for the sample bleached in a $10 \%$ Hydrogen peroxide solution, with a $\mathrm{pH}$ of 10 against the $4.71 \mathrm{mmol} / \mathrm{g}$ oil for the unbleached sample.
\end{abstract}

\section{Keywords}

Walnut Meal, Whitening, Color Parameters 


\section{Introduction}

Walnut, a nut plant with the scientific name Juglans regia L., is the most favorable crop for temperate regions [1]. There is a great diversity of walnut genotypes that differ in terms of forestry, productivity, physical and chemical characteristics of nuts. The nutritional importance of walnut is related to the seed (core) [2] [3]. Walnuts are among the most widely consumed and commercially grown in the world, have many health benefits, including reducing the risk of cardiovascular disease, the treatment of type II diabetes and the prevention and treatment of certain cancers and reducing age-related symptoms and other neurological disorders [4] [5] [6] [7].

Juglans regia $L$. nuts are widely used in human nutrition and considered as strategic foods, included in the FAO list of priority plants [8]. Walnut kernels are a very concentrated food, with an energy value of $650-700 \mathrm{kcal} / 100 \mathrm{~g}$, much higher than all foods of plant origin [9]-[14]. Walnuts are commonly found in our diet and have been known for their nutritional properties for a long time. Walnuts have traditionally been known for their lipid profile, which has been linked to a wide range of biological properties and health-promoting effects [15] [16] [17] [18].

The walnut oil extraction residue-meal, is rich in protein (unusually rich in arginine, glutamic and aspartic acids) and has been used in the formulation of various functional foods [19]. Walnut meal is a valuable product, but after pressing and storage it acquires a less attractive appearance and this negatively influences the organoleptic characteristics of food products where the use of walnut meal is essential [16] [20] [21]. After pressing, the walnut meal has a gray-yellow color and after storage, the color intensifies. Its use as an ingredient for food would negatively influence the color of the products, so its whitening would be a reasonable way, and the whitened meal would be an ideal ingredient in the preparation of pastries, preserving the aspectual qualities of the product but also enriching them from the nutritional aspect [16] [21] [22].

Given that the specific color of the walnut meal is determined by the chromophores of lignins in the core membrane, some paper whitening agents could be used. Of these, the most convenient seems to be hydrogen peroxide, which has an effective oxidizing agent, non-toxic and environmentally friendly [23] [24].

Hydrogen peroxide is a colorless liquid, used mainly as a whitening agent for different food, including oilseed meals. Upon decomposition, hydrogen peroxide forms water and oxygen and is therefore a clean environmental agent. Whitening involves the neutralization of chromophores in plant cell pigments. Chromophores are a set of alternating conjugated chains with single and double bonds often-containing heteroatoms (other than carbon-nitrogen, oxygen, sulfur, etc.). Thanks to the interaction with light rays, chromophores are responsible for the color of pigments [25].

\section{Materials and Methods}

The choice of the bleaching process was based on Hydrogen Peroxide treatment 
at various pHs. Indeed, such a treatment is effective in discoloring many organic substances containing carbonyl groups. Hydrogen Peroxide acts as an oxidant against lignin chromophore compounds. In addition, Hydrogen Peroxide bleaching limits yield losses and generates effluents that are not contaminated with the reagent, which is converted to water and oxygen. To do this, the walnut meal is suspended in a solution of Hydrogen Peroxide so as to obtain the following concentrations: $2.5 \% ; 5 \%$ and $10 \%(\mathrm{w} / \mathrm{v})$. The meal is then mixed with dilute Hydrogen Peroxide solutions at the following concentrations: $3 \%, 6 \%$ and $10 \%(\mathrm{v} / \mathrm{v})$ at $\mathrm{pH} \mathrm{3,7}$ and 10 . After seeing the mixture mixed and shaken manually for 1 hour, the solutions were placed in a forced air oven and set at $60^{\circ} \mathrm{C}$ for $24 \mathrm{~h}$.

After removing the hydrogen peroxide and meal drying, the color parameters were determined using the CIE Lab color system.

The color of the products can be determined not only visually but also instrumentally. The color of any food, in the CIE Lab 76 method, can be represented graphically in an orthogonal Cartesian system, whose coordinate axes are even the chromatic parameters $L$, $a$ and $b$ (Figure 1) [26] [27] [28].

- $L^{*}$ : expresses the brightness of the color of the object;

- $a^{*}$ : expresses the color values on the red-green color axis;

- $b^{*}$ : expresses the color values on the blue-yellow color axis.

In order to be able to whiten the walnut meal, several steps were performed: identify the problem, identify the factors and levels that affect the response variables, perform statistically designed experiments and, finally, analyze the experimental data with statistical tools.

A Box-Behnken-type experimental plan was used to conduct the study. This is a quadratic model, which allows the identification of the optimal value by varying a number of factors (independent variables). In the case of whitening of walnut meal as variables were: $\mathrm{pH}(3,7$ and 10), concentrations of hydrogen peroxide $(3 \%, 6 \%$ and $10 \% \mathrm{v} / \mathrm{v})$ and concentration of meal $(2.5 \%, 5 \%$ and $10 \%$ $\mathrm{w} / \mathrm{v})$.

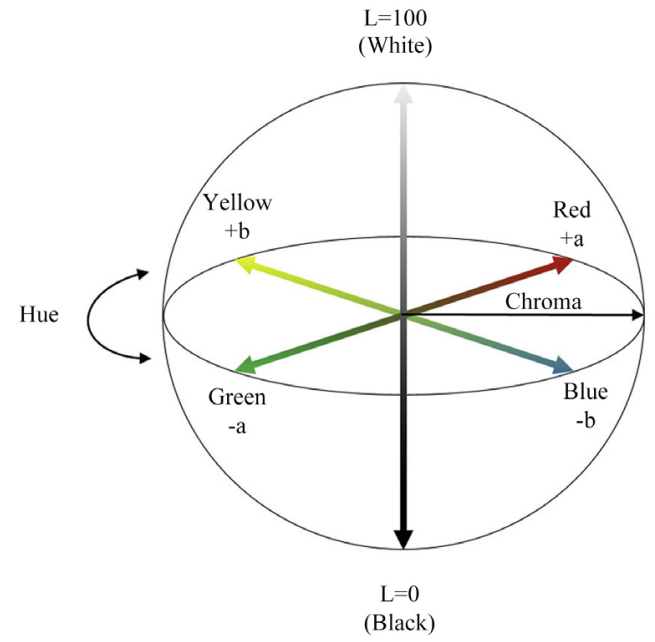

Figure 1. Linear color space CIE Lab 76. 
A statistical modeling technique-the surface area method (MRS) - was used to analyze the obtained results. MRS is an empirical modeling technique used to analyze multiple regressions and identify the major effects of independent variables on walnut meal whitening, and establish the combination of variables that ensures the highest values of brightness $L$ and minimum values for the browning index (BI) (Table 1).

Whitening performance was assessed by analyzing the responses $(Y)$ of the 27 measurements, which depend on the input factors. The behavior of the response surface was studied for the response function ( $Y i)$, which is a second-degree polynomial equation:

$$
Y=b_{0}+b_{1} x_{1}+b_{2} x_{2}+b_{11} x_{1} x_{2}+b_{12} x_{1}^{2}+\cdots+b_{22} x_{2}^{2},
$$

The actual treatment of the walnut meal with hydrogen peroxide lasted 60 minutes after it was dried, and the chromatic parameters of the bleached meal were determined using a colorimeter. The bleaching conditions, the experimental values of the color parameters $\left(L^{*}, a^{*}, b^{*}\right)$ and the calculated values of the bleaching indices $(B I, W I, S I, \Delta E)$ are presented in Table 2.

\section{Results}

The regression results indicate the direction, magnitude and statistical significance of the relationship between an independent variable and a response. The sign of each coefficient indicates the direction of the relationship. The coefficients represent the average evolution of the response to a change with a unit of the independent variable, without modifying the other variables in the model [29].

To a better visualization, pictures of the unbleached and bleached meal were taken and presented in Figure 2.

To illustrate the main and interactive effects of the independent variables on the values of the color descriptors $\left(L^{*}, a^{*}, b^{*}, B I, W I, S I, \Delta E\right)$ of the walnut meal, the $3 \mathrm{D}$ response surfaces were constructed. These graphs were obtained by fixing one of the variables to the coded zero level and varying the other two variables. The $3 \mathrm{D}$ response surfaces of the $\mathrm{L}$ brightness as a function of $\mathrm{pH}, \mathrm{H}_{2} \mathrm{O}_{2}$ and meal concentration in the bleaching medium are shown in the figures.

Figure 3 shows the effects of $C_{\mathrm{H}_{2} \mathrm{O}_{2}}$ and $C_{\mathrm{M}}$ on the brightness $L^{*}$ of the walnut meal, which shows the linear and square effects for $C_{\mathrm{H}_{2} \mathrm{O}_{2}}$, while for $C_{\mathrm{M}}$, the effect is rather linear, and the interaction effect between these two variables is quite little.

Figure 4 shows that the $C_{\mathrm{M}}-C_{\mathrm{PH}}$ combination does not have a significant effect on lightness.

Figure 5 shows that the linear effects of $\mathrm{pH}$ and peroxide concentration are significant, as are two quadratic effects.

Factors influencing the bleaching of the walnut meal with hydrogen peroxide are: the concentration of the meal in the bleaching medium, the $\mathrm{pH}$ values, ambient temperature and the duration of the bleaching process. 
Table 1. Walnut meal bleaching conditions, the experimental values of the color parameters and the calculated values of the bleaching indices.

\begin{tabular}{|c|c|c|c|c|c|c|c|c|c|c|}
\hline \multicolumn{3}{|c|}{ Whitening process parameters } & \multicolumn{3}{|c|}{ Color parameters } & \multicolumn{5}{|c|}{ Calculated whitening indices } \\
\hline $\begin{array}{c}\mathrm{pH} \text { value } \\
\left(C_{\mathrm{PH}}\right)\end{array}$ & $C_{\mathrm{H}_{2} \mathrm{O}_{2}}, \%$ & $\begin{array}{l}\text { Walnut meal } \\
\text { concentration, } \\
\left(C_{\mathrm{M}}, \%\right)\end{array}$ & $L$ & $a$ & $b$ & $W I$ & $S I$ & $\Delta E$ & $x$ & $B I$ \\
\hline Unbleached & alnut meal & 2.5 & 42.97 & 8.70 & 24.70 & 37.30 & 26.10 & - & 0.47 & 96.68 \\
\hline 3 & $3 \%$ & 2.5 & 51.98 & 8.51 & 30.75 & 44.30 & 31.90 & 0.20 & 0.48 & 97.20 \\
\hline 3 & $3 \%$ & 5 & 49.27 & 8.75 & 28.23 & 41.30 & 29.50 & 7.50 & 0.47 & 94.42 \\
\hline 3 & $3 \%$ & 10 & 43.73 & 6.50 & 25.40 & 37.90 & 26.20 & 2.10 & 0.47 & 93.81 \\
\hline 3 & $6 \%$ & 2.5 & 60.55 & 8.13 & 29.45 & 50.10 & 30.50 & 18.20 & 0.44 & 74.56 \\
\hline 3 & $6 \%$ & 5 & 55.99 & 7.21 & 27.02 & 47.80 & 27.90 & 1.50 & 0.43 & 73.46 \\
\hline 3 & $6 \%$ & 10 & 45.63 & 5.32 & 20.90 & 41.50 & 21.50 & 5.00 & 0.43 & 68.22 \\
\hline 3 & $10 \%$ & 2.5 & 72.89 & 2.90 & 19.50 & 66.40 & 19.70 & 6.20 & 0.37 & 33.43 \\
\hline 3 & $10 \%$ & 5 & 66.00 & -2.00 & 23.20 & 58.80 & 23.20 & 10.80 & 0.38 & 39.68 \\
\hline 3 & $10 \%$ & 10 & 50.10 & 5.10 & 26.10 & 43.40 & 26.50 & 3.60 & 0.44 & 78.39 \\
\hline 7 & $3 \%$ & 2.5 & 52.33 & 8.75 & 31.00 & 42.10 & 32.20 & 11.20 & 0.48 & 97.64 \\
\hline 7 & $3 \%$ & 5 & 50.01 & 9.12 & 29.15 & 41.40 & 30.50 & 8.30 & 0.47 & 96.81 \\
\hline 7 & $3 \%$ & 10 & 48.25 & 9.50 & 28.55 & 40.10 & 30.00 & 6.50 & 0.48 & 99.75 \\
\hline 7 & $6 \%$ & 2.5 & 61.13 & 8.88 & 29.70 & 50.20 & 30.00 & 18.80 & 0.44 & 75.31 \\
\hline 7 & $6 \%$ & 5 & 56.33 & 7.32 & 27.25 & 47.90 & 28.20 & 1.90 & 0.44 & 73.76 \\
\hline 7 & $6 \%$ & 10 & 46.63 & 7.12 & 21.90 & 41.80 & 23.00 & 3.20 & 0.43 & 73.00 \\
\hline 7 & $10 \%$ & 2.5 & 73.12 & 3.10 & 19.88 & 66.40 & 20.10 & 7.30 & 0.37 & 34.21 \\
\hline 7 & $10 \%$ & 5 & 66.52 & 1.20 & 20.20 & 60.80 & 20.20 & 8.70 & 0.37 & 36.67 \\
\hline 7 & $10 \%$ & 10 & 50.75 & 5.10 & 26.10 & 44.00 & 26.50 & 3.60 & 0.44 & 77.04 \\
\hline 10 & $3 \%$ & 2.5 & 56.33 & 8.80 & 31.55 & 45.40 & 32.70 & 14.90 & 0.46 & 90.19 \\
\hline 10 & $3 \%$ & 5 & 52.01 & 9.33 & 29.19 & 43.00 & 30.60 & 10.10 & 0.47 & 92.19 \\
\hline 10 & $3 \%$ & 10 & 49.11 & 10.50 & 29.00 & 40.50 & 30.80 & 6.70 & 0.48 & 100.77 \\
\hline 10 & $6 \%$ & 2.5 & 63.76 & 9.34 & 30.43 & 51.70 & 31.80 & 21.50 & 0.44 & 73.87 \\
\hline 10 & $6 \%$ & 5 & 57.89 & 8.12 & 27.39 & 49.10 & 28.50 & 15.10 & 0.43 & 72.66 \\
\hline 10 & $6 \%$ & 10 & 47.55 & 7.02 & 22.11 & 42.60 & 23.10 & 3.00 & 0.43 & 71.80 \\
\hline 10 & $10 \%$ & 2.5 & 82.12 & 3.89 & 22.18 & 71.20 & 22.50 & 5.40 & 0.37 & 34.35 \\
\hline 10 & $10 \%$ & 5 & 67.77 & 2.20 & 20.89 & 61.50 & 21.00 & 7.50 & 0.38 & 38.43 \\
\hline 10 & $10 \%$ & 10 & 60.15 & 6.10 & 30.10 & 49.60 & 30.70 & 2.60 & 0.44 & 74.55 \\
\hline
\end{tabular}


Table 2. Polynomial equations ${ }^{*}$ of second degree for the color descriptors of the walnut meal.

\begin{tabular}{|c|c|}
\hline Parameter and index name & Polynomial equation \\
\hline Lightness, $L$, & $\begin{aligned} L= & 53.83+1.66 * C_{\mathrm{H}_{2} \mathrm{O}_{2}}-1.46 * C_{\mathrm{PH}_{1}}-1.05 * C_{\mathrm{M}}+0.04 * C_{\mathrm{H}_{2} \mathrm{O}_{2}} * C_{\mathrm{PH}}-0.31 * C_{\mathrm{H}_{2} \mathrm{O}_{2}} * C_{\mathrm{M}} \\
& +0.004 C_{\mathrm{PH}} * C_{\mathrm{M}}+0.002 * C_{\mathrm{H}_{2} \mathrm{O}_{2}} * C_{\mathrm{M}} * C_{\mathrm{PH}}+0.14 * C_{\mathrm{H}_{2} \mathrm{O}_{2}}^{2}+0.131 * C_{\mathrm{PH}}^{2}+0.07 * C_{\mathrm{M}}^{2}\end{aligned}$ \\
\hline a value & $\begin{aligned} a= & 15.85-0.39 * C_{\mathrm{H}_{2} \mathrm{O}_{2}}-0.29 * C_{\mathrm{pH}}-2.3 * C_{\mathrm{M}}+0.08 * C_{\mathrm{H}_{2} \mathrm{O}_{2}} * C_{\mathrm{PH}}+0.14 * C_{\mathrm{H}_{2} \mathrm{O}_{2}} * C_{\mathrm{M}} \\
& +0.1 C_{\mathrm{PH}} * C_{\mathrm{M}}-0.01 * C_{\mathrm{H}_{2} \mathrm{O}_{2}} * C_{\mathrm{M}} * C_{\mathrm{PH}}-0.1 * C_{\mathrm{H}_{2} \mathrm{O}_{2}}^{2}-0.01 * C_{\mathrm{PH}}^{2}+0.1 * C_{\mathrm{M}}^{2}\end{aligned}$ \\
\hline$b$ value & $\begin{aligned} b= & 45.05-2.5 * C_{\mathrm{H}_{2} \mathrm{O}_{2}}-0.4 * C_{\mathrm{PH}}-2.67 * C_{\mathrm{M}}-0.001 * C_{\mathrm{H}_{2} \mathrm{O}_{2}} * C_{\mathrm{PH}}+0.22 * C_{\mathrm{H}_{2} \mathrm{O}_{2}} * C_{\mathrm{M}} \\
& +0.04 C_{\mathrm{PH}} * C_{\mathrm{M}}-0.001 * C_{\mathrm{H}_{2} \mathrm{O}_{2}} * C_{\mathrm{M}} * C_{\mathrm{PH}}+0.03 * C_{\mathrm{H}_{2} \mathrm{O}_{2}}+0.03 * C_{\mathrm{PH}}^{2}+0.06 * C_{\mathrm{M}}^{2}\end{aligned}$ \\
\hline Whitening index, WI & $\begin{aligned} W I= & 39.52-2.07 * C_{\mathrm{H}_{2} \mathrm{O}_{2}}-1.29 * C_{\mathrm{PH}}+0.44 * C_{\mathrm{M}}+0.05 * C_{\mathrm{H}_{2} \mathrm{O}_{2}} * C_{\mathrm{pH}}-0.35 * C_{\mathrm{H}_{2} \mathrm{O}_{2}} * C_{\mathrm{M}} \\
& -0.01 C_{\mathrm{PH}} * C_{\mathrm{M}}+0.0007 * C_{\mathrm{H}_{2} \mathrm{O}_{2}} * C_{\mathrm{M}} * C_{\mathrm{PH}}+0.14 * C_{\mathrm{H}_{2} \mathrm{O}_{2}}+0.09 * C_{\mathrm{PH}}^{2}+0.006 * C_{\mathrm{M}}^{2}\end{aligned}$ \\
\hline Saturation index, $S I$ & $\begin{aligned} S I= & 47.39-2.6 * C_{\mathrm{H}_{2} \mathrm{O}_{2}}-0.64 * C_{\mathrm{PH}}-2.87 * C_{\mathrm{M}}+0.007 * C_{\mathrm{H}_{2} \mathrm{O}_{2}} * C_{\mathrm{PH}}+0.24 * C_{\mathrm{H}_{2} \mathrm{O}_{2}} * C_{\mathrm{M}} \\
& +0.07 C_{\mathrm{PH}} * C_{\mathrm{M}}-0.003 * C_{\mathrm{H}_{2} \mathrm{O}_{2}} * C_{\mathrm{M}} * C_{\mathrm{PH}}+0.022 * C_{\mathrm{H}_{2} \mathrm{O}_{2}}^{2}+0.04 * C_{\mathrm{PH}}^{2}+0.06 * C_{\mathrm{M}}^{2}\end{aligned}$ \\
\hline Total color difference, $\Delta E$ & $\begin{aligned} \Delta E= & -9.84+4.97 * C_{\mathrm{H}_{2} \mathrm{O}_{2}}+2.7 * C_{\mathrm{PH}}-0.54 * C_{\mathrm{M}}-0.32 * C_{\mathrm{H}_{2} \mathrm{O}_{2}} * C_{\mathrm{PH}}-0.13 * C_{\mathrm{H}_{2} \mathrm{O}_{2}} * C_{\mathrm{M}} \\
& -0.25 C_{\mathrm{PH}} * C_{\mathrm{M}}+0.02 * C_{\mathrm{H}_{2} \mathrm{O}_{2}} * C_{\mathrm{M}} * C_{\mathrm{PH}}-0.23 * C_{\mathrm{H}_{2} \mathrm{O}_{2}}+0.03 * C_{\mathrm{pH}}^{2}+0.08 * C_{\mathrm{M}}^{2}\end{aligned}$ \\
\hline Browning index, $B I$ & $\begin{aligned} B I= & 163.07-16.57 * C_{\mathrm{H}_{2} \mathrm{O}_{2}}-0.63 * C_{\mathrm{PH}}-9.94 * C_{\mathrm{M}}+0.26 * C_{\mathrm{H}_{2} \mathrm{O}_{2}} * C_{\mathrm{PH}}+1.16 * C_{\mathrm{H}_{2} \mathrm{O}_{2}} * C_{\mathrm{M}} \\
& +0.4 C_{\mathrm{PH}} * C_{\mathrm{M}}-0.04 * C_{\mathrm{H}_{2} \mathrm{O}_{2}} * C_{\mathrm{M}} * C_{\mathrm{PH}}+0.25 * C_{\mathrm{H}_{2} \mathrm{O}_{2}}^{2}-0.12 * C_{\mathrm{PH}}^{2}+0.3 * C_{\mathrm{M}}^{2}\end{aligned}$ \\
\hline
\end{tabular}

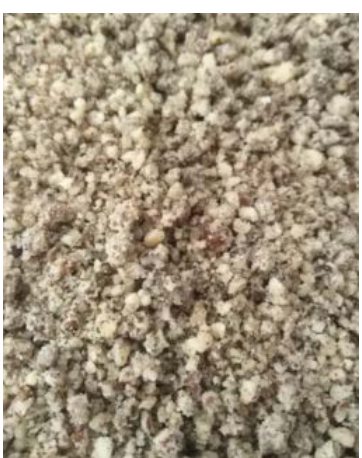

(a)

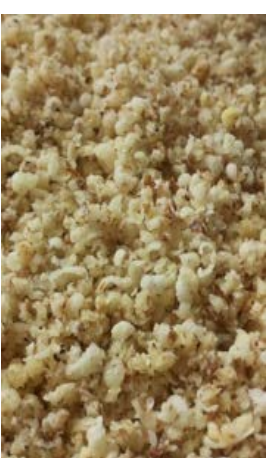

(b)

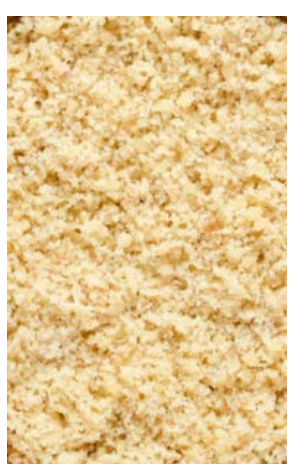

(c)

Figure 2. Walnut meal samples: (a) unbleached; (b) bleached $C_{\mathrm{H}_{2} \mathrm{O}_{2}}=$ $10 \%, \mathrm{pH}=3$; (c) bleached $C_{\mathrm{H}_{2} \mathrm{O}_{2}}=10 \%, \mathrm{pH}=10$.

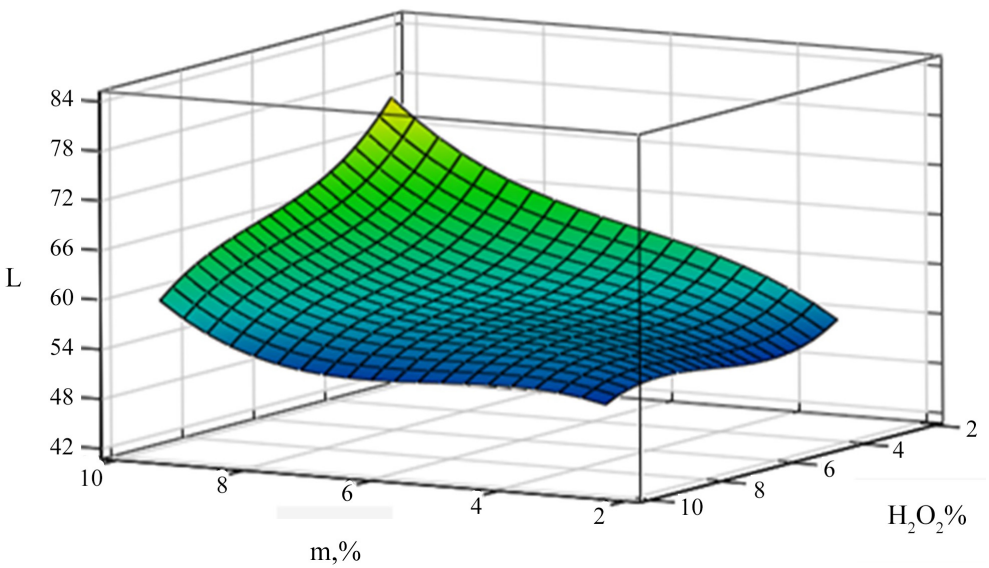

Figure 3. 3D Lightness $(L)$ response surface as a function of $\mathrm{H}_{2} \mathrm{O}_{2}$ and meal concentration in the bleaching medium. 


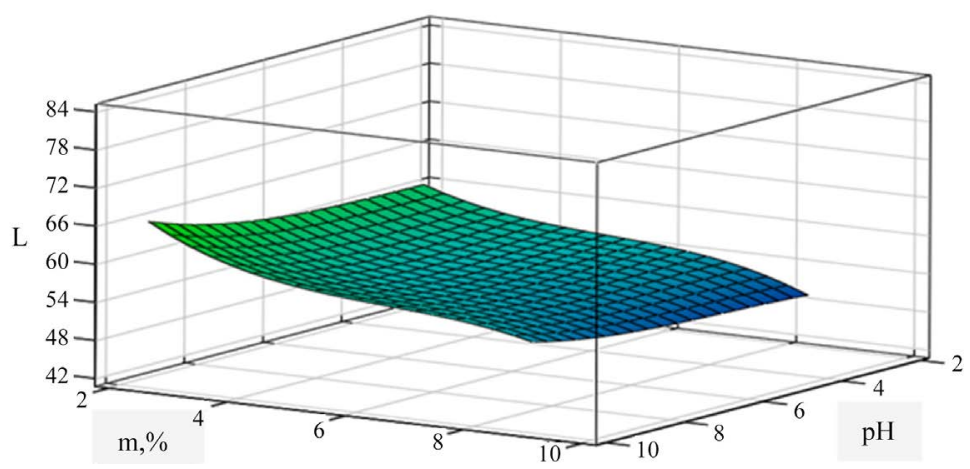

Figure 4. 3D Lightness $(L)$ response surface as a function of $\mathrm{pH}$ and meal concentration in the bleaching medium.

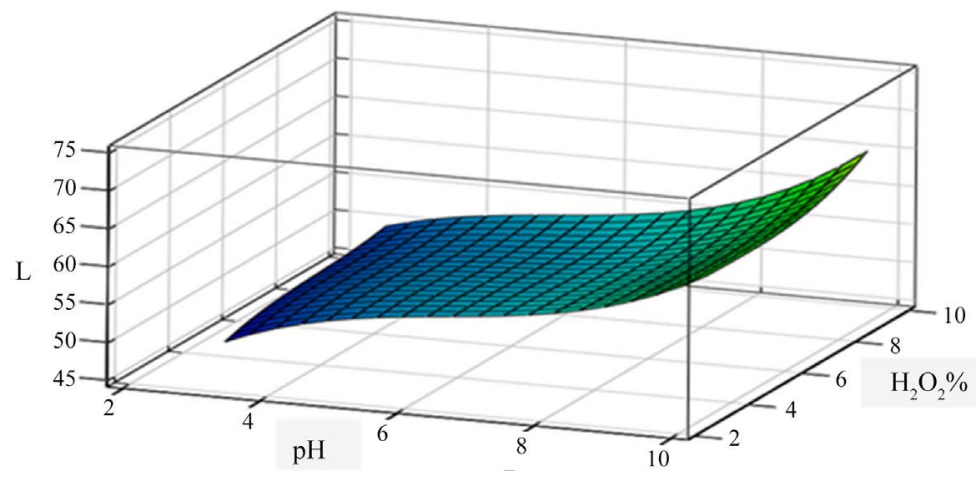

Figure 5. 3D Lightness $(L)$ response surface as a function of $\mathrm{pH}$ and $\mathrm{H}_{2} \mathrm{O}_{2}$ concentration in the bleaching medium.

The $\mathrm{pH}$ of the medium plays an important role in the catalytic oxidation with hydrogen peroxide [30] [31] and the brightness of the walnut meal increases. In acidic environments, the rate of discoloration is much slower, and complete discoloration is not achieved even after long periods of treatment with hydrogen peroxide.

Thus, the bleaching process with hydrogen peroxide is determined by the presence in the aqueous medium of the perhydroxyl ion $\mathrm{HOO}^{-}$, which is stable only in alkaline medium. Therefore, the $\mathrm{pH}$ value of the reaction medium is a determining parameter for the kinetics and duration of bleaching, and the bleaching solution must be sufficiently alkaline to maintain the concentration of perhydroxyl ions. A certain role is played by temperature, the increase of which accelerates the formation of perhydroxyl anions, which in turn react with the peroxide as follows:

$$
\mathrm{H}_{2} \mathrm{O}_{2}+\mathrm{HOO}^{-}>\mathrm{H}_{2} \mathrm{O}+\mathrm{OH}^{-}+\mathrm{O}_{2}
$$

In this way the temperature and the contact time of the walnut meal with the bleaching solution are two interdependent variables and within certain limits their increase can cause the same effect on the obtained bleaching level. The effect of hydrogen peroxide concentration on the bleaching process was studied at three concentrations: $3 \%, 6 \%$ and $10 \%(\mathrm{v} / \mathrm{v})$. The concentration of meal in the bleaching medium was $2.5 \%, 5 \%$ and $10 \%(\mathrm{~m} / \mathrm{v})$, and $\mathrm{pH}$ values: 3,7 and 10 . The 
results show that increasing the concentration of hydrogen peroxide increases the whiteness of the product. However, the whiteness of the meal was higher when its concentrations were $2.5 \%$ and $5 \%$, regardless of the combinations of $\mathrm{pH}$ and peroxide concentration. This indicates the existence of an optimal concentration of peroxide (approx. 10\%), at which bleaching rate is highest.

In turn, some of the mentioned groups can form complex and more colorful substances, which are also involved in the bleaching process. The active agent in the hydrogen peroxide bleaching process is the perhydroxyl anion $\left(\mathrm{HOO}^{-}\right)$:

$$
\mathrm{H}_{2} \mathrm{O}_{2}+\mathrm{OH}^{-}>\mathrm{H}_{2} \mathrm{O}+\mathrm{HOO}^{-}
$$

It mainly attacks carbonyl groups. Among the compounds resulting from the oxidation reaction of the carbonyl groups are quinones. Perhydroxyl anions oxidize quinones and convert them to carboxylic acid or hydroxyl quinones, which retain the browning process [32].

The increase in the concentration of hydrogen peroxide leads to a high rate of oxidation of pigments with hydroxyl radicals, and the reaction equilibrium shifts to conditions that lead to the formation of more hydroxyl radicals.

In the case of a constant peroxide concentration and change (enlargement) of the walnut meal concentration, the bleaching capacity decreases due to the limited amount of bleaching agents available per unit of treated product. In general, however, the bleaching process is like a $1^{\text {st }}$ order reaction. These radicals are active agents that participate in the lignin degradation reaction [33] [34]. Several authors have found that non-esterified phenolic units can be oxidized in an alkaline medium by hydrogen peroxide, forming ortho- and para-benzoquinone intermediates, which subsequently oxidize to form acidic fragments. At the same time the esterified phenolic units are stable in the alkaline environment [35]. In this order, the highest value for the Lightness $L=82.12$ was reached when bleaching the meal with a $10 \%$ hydrogen peroxide solution, with a $\mathrm{pH}=10$, and meal concentration of $2.5 \%(\mathrm{~m} / \mathrm{v})$. The results obtained for Whitening Index $(W I=71.20)$ also confirm that the most effective treatment is with hydrogen peroxide with a concentration of $10 \%$ and a $\mathrm{pH}$ of 10 .

The walnut meal quality was studied in terms of lipids oxidation. As mentioned above, walnut meal is made up mostly of fat (about 40\%) and protein (about 28\%). Assuming that the treatment of meal with hydrogen peroxide could have a negative impact on the oxidation of meal lipids, experiments were performed to determine the evolution of the oil peroxide index during bleaching.

Thus, the bleached (under different conditions) and unbleached walnut meal was mixed with walnut oil (with the predetermined peroxide index), and from the obtained mixture after 45 minutes (to equilibrate the concentration), the required volume of oil was extracted and the peroxide value was determined.

The peroxide value of the walnut meal lipids was calculated based on the proportions of walnut oil and meal. The obtained results are presented in Table 3. 
Table 3. Impact of the bleaching process with oxygen peroxide $\left(\mathrm{CH}_{2} \mathrm{O}_{2}=10 \%\right)$ on the peroxide value of walnut meal.

\begin{tabular}{|c|c|c|c|c|c|}
\hline \multirow{2}{*}{$\begin{array}{l}\mathrm{pH} \text { values of bleaching } \\
\text { medium }\end{array}$} & \multicolumn{5}{|c|}{$\begin{array}{l}\text { Whitening time (min.) and values of } \\
\text { walnut meal peroxide index (mmol/g oil) }\end{array}$} \\
\hline & $0 \mathrm{~min}$. & $10 \mathrm{~min}$. & $20 \mathrm{~min}$. & $30 \mathrm{~min}$. & $60 \mathrm{~min}$. \\
\hline $\mathrm{pH}-10$ & & $4.79 \pm 0.33$ & $4.83 \pm 0.33$ & $4.85 \pm 0.33$ & $4.91 \pm 0.34$ \\
\hline pH-7 & $4.71 \pm 0.30$ & $4.75 \pm 0.33$ & $4.78 \pm 0.33$ & $4.79 \pm 0.33$ & $4.86 \pm 0.34$ \\
\hline $\mathrm{pH}-3$ & & $4.73 \pm 0.33$ & $4.76 \pm 0.33$ & $4.77 \pm 0.33$ & $4.87 \pm 0.34$ \\
\hline
\end{tabular}

The data in the table show that the treatment with hydrogen peroxide does not affect in any way the value of the peroxide index of the lipids in the walnut meal. Moreover, this can be easily explained by the fact that hydrogen peroxide is an aqueous medium, in which the solubility of lipids is practically zero, and the process of lipid oxidation can take place only at the interface of lipids with the aqueous medium, but what is quite slow. Similar results have been reported in the case of palm bunch bleaching [27].

\section{Conclusions}

In food technology, walnut meal can be used as a valuable product, and in order not to influence the appearance of the final products, bleached meal is used. Thus, the chromatic parameters, the bleaching conditions as well as the $3 \mathrm{D}$ response surfaces of the $\mathrm{L}$ brightness as a function of $\mathrm{pH}$, the $\mathrm{H}_{2} \mathrm{O}_{2}$ and meal concentration in the bleaching medium were determined.

As bleaching is influenced by $\mathrm{pH}$, the $\mathrm{pH}$ value of the reaction medium has been shown to be a determinant of the kinetics and duration of bleaching, and the bleaching solution must be sufficiently alkaline to maintain the concentration of peroxide ions. The peroxide concentration influences the bleaching process and the results showed that increasing the peroxide concentration increases the whiteness of the product. The obtained results showed that an alkaline medium, with the hydrogen peroxide concentration of $10 \%$ and $2.5 \%$ meal concentration allows obtaining the best color parameters in terms of Lightness (82.20) and Whitening Index (71.20).

As walnut meal consists mostly of fats (about $40 \%$ ) and protein (about 28\%) it has been shown that hydrogen peroxide treatment does not affect in any way the value of the lipid peroxide index in the meal. The highest peroxide value (4.91 $\mathrm{mmol} / \mathrm{g}$ oil) was recorded for the sample bleached in a $10 \%$ Hydrogen peroxide solution, with a $\mathrm{pH}$ of 10 against the $4.71 \mathrm{mmol} / \mathrm{g}$ oil for the unbleached sample, so the bleached meal can be used in the manufacture of products only positively influencing the final result.

\section{Funding}

The research was funded by State Project 20.80009.5107.10 "Personalized nutrition and intelligent technologies for my wellbeing”, running at Technical Uni- 
versity of Moldova.

\section{Conflicts of Interest}

The authors declare no conflicts of interest regarding the publication of this paper.

\section{References}

[1] Chen, C., Venkitasamy, C., Zhang, W., et al. (2020) Effect of Step-Down Temperature Drying on Energy Consumption and Product Quality of Walnuts. Journal of Food Engineering, 285, Article ID: 110105. https://doi.org/10.1016/j.jfoodeng.2020.110105

[2] Amaral, J.S., Casal, S., Pereira, J.A., et al. (2003) Determination of Sterol and Fatty Acid Compositions, Oxidative Stability, and Nutritional Value of Six Walnut (Juglans regia L.) Cultivars Grown in Portugal. Journal of Agricultural and Food Chemistry, 51, 7698-7702. https://doi.org/10.1021/jf030451d

[3] Miraliakbari, H. and Shahidi, F. (2008) Oxidative Stability of Tree Nut Oils. Journal of Agricultural and Food Chemistry, 56, 4751-4759. https://doi.org/10.1021/jf8000982

[4] Pan, A., Sun, Q., Manson, J.E., et al. (2013) Walnut Consumption Is Associated with Lower Risk of Type 2 Diabetes in Women. The Journal of Nutrition, 143, 512-518. https://doi.org/10.3945/jn.112.172171

[5] Iwamoto, M., Imaizumi, K., Sato, M., et al. (2002) Serum Lipid Profiles in Japanese Women and Men during Consumption of Walnuts. European Journal of Clinical Nutrition, 56, 629-637. https://doi.org/10.1038/sj.ejcn.1601400

[6] Ros, E., Núñez, I., Pérez-Heras, A., et al. (2004) A Walnut Diet Improves Endothelial Function in Hypercholesterolemic Subjects: A Randomized Crossover Trial. Circulation, 109, 1609-1614. https://doi.org/10.1161/01.CIR.0000124477.91474.FF

[7] Reiter, R.J., Manchester, L.C. and Tan, D. (2005) Melatonin in Walnuts: Influence on Levels of Melatonin and Total Antioxidant Capacity of Blood. Nutrition, 21, 920-924. https://doi.org/10.1016/j.nut.2005.02.005

[8] Gandev, S. (2008) Budding and Grafting of the Walnut (Juglans regia L.) and Their Effectiveness in Bulgaria. Bulgarian Journal of Agricultural Science, 13, 683-689.

[9] Grosu, C., Boaghi, E., Paladi, D., Deseatnicova, O. and Reşitca, V. (2012) Prospects of Using Walnut Oil Cake in Food Industry. Conferinta "Modern Technologies, in the Food Industry", Chisinau, 1-3 November 2012, 362-365.

[10] Özcan, M.M. (2009) Some Nutritional Characteristics of Fruit and Oil of Walnut (Juglans regia L.) Growing in Turkey. Iranian Journal of Chemistry and Chemical Engineering, 28, 57-62.

[11] Cannella, C. and Dernini, S. (2005) Walnut: Insights and Nutritional Value. Acta Horticulturae, 705, 547-550. https://doi.org/10.17660/ActaHortic.2005.705.80

[12] Fatima, T., Showkat, U. and Hussain, S.Z. (2018) Nutritional and Health Benefits of Walnuts. Journal of Pharmacognosy and Phytochemistry, 7, 1269-1271.

[13] Taha, N.A. (2011) Utility and Importance of Walnut, Juglans regia Linn: A Review. African Journal of Microbiology Research, 5, 5796-5805. https://doi.org/10.5897/AJMR11.610

[14] Queirós, C.S.G.P., Cardoso, S., Lourenço, A., Ferreira, J., Miranda, I., Lourenço, M.J.V. and Pereira, H. (2020) Characterization of Walnut, Almond, and Pine Nut 
Shells Regarding Chemical Composition and Extract Composition. Biomass Conversion and Biorefinery. https://doi.org/10.1007/s13399-019-00424-2

[15] Hayes, D., Angove, M.J., Tucci, J. and Dennis, C. (2016) Walnuts (Juglans regia) Chemical Composition and Research in Human Health. Critical Reviews in Food Science and Nutrition, 56, 1231-1241. https://doi.org/10.1080/10408398.2012.760516

[16] Xu, J., Jin, F., Hao, J., et al. (2020) Preparation of Soy Sauce by Walnut Meal Fermentation: Composition, Antioxidant Properties, and Angiotensin-Converting Enzyme Inhibitory Activities. Food Science \& Nutrition, 8, 1665-1676. https://doi.org/10.1002/fsn3.1453

[17] Liu, B., Liang, J., Zhao, D., et al. (2020) Morphological and Compositional Analysis of Two Walnut (Juglans regia L.) Cultivars Growing in China. Plant Foods for Human Nutrition, 75, 116-123. https://doi.org/10.1007/s11130-019-00794-y

[18] Wang, X., Chen, H., Li, S., et al. (2016) Physico-Chemical Properties, Antioxidant Activities and Antihypertensive Effects of Walnut Protein and Its Hydrolysate: Properties of Walnut Protein Hydrolysate. Journal of the Science of Food and Agriculture, 96, 2579-2587. https://doi.org/10.1002/jsfa.7379

[19] Csizmadi, I., Lin, P.-H., Freeman, M., et al. (2020) Walnuts for Power: A Protocol for the Polyphenols, Omega-3 Fatty Acids, Weight Loss, and Energy Randomized Controlled Trial. Current Developments in Nutrition, 4, 316. https://doi.org/10.1093/cdn/nzaa044_015

[20] Pycia, K., Kapusta, I. and Jaworska, G. (2020) Walnut Oil and Oilcake Affect Selected the Physicochemical and Antioxidant Properties of Wheat Bread Enriched with Them. Journal of Food Processing and Preservation, 44, e14573. https://doi.org/10.1111/jfpp.14573

[21] Pop, A., Păucean, A., Socaci, S.A., et al. (2020) Quality Characteristics and Volatile Profile of Macarons Modified with Walnut Oilcake By-Product. Molecules, 25, 2214. https://doi.org/10.3390/molecules25092214

[22] Kaletnik, H., Lutsiak, V., Melnichuk, O., Dovhan, Y. and Malicki, M. (2019) Organizational Basis of the Development of Innovative Functional Food Products by the Ukrainian Enterprises of Deep Walnut Processing. Ukrainian Food Journal, 8, 169-180.

[23] Ma, C.-Y., Wang, H.-M., Wen, J.-L., et al. (2020) Structural Elucidation of Lignin Macromolecule from Abaca during Alkaline Hydrogen Peroxide Delignification. International Journal of Biological Macromolecules, 144, 596-602. https://doi.org/10.1016/j.ijbiomac.2019.12.080

[24] Wang, H., Wang, B., Sun, D., et al. (2019) Unraveling the Fate of Lignin from Eucalyptus and Poplar during Integrated Delignification and Bleaching. ChemSusChem, 12, 1059-1068. https://doi.org/10.1002/cssc.201802592

[25] Hermansyah, H., Putri, D.N., Prasetyanto, A., et al. (2019) Delignification of Oil Palm Empty Fruit Bunch Using Peracetic Acid and Alkaline Peroxide Combined with the Ultrasound. International Journal of Technology, 10, 1523-1532. https://doi.org/10.14716/ijtech.v10i8.3464

[26] Durmus, D. (2020) CIELAB Color Space Boundaries under Theoretical Spectra and 99 Test Color Samples. Color Research and Application, 45, 796-802. https://doi.org/10.1002/col.22521

[27] Li, M., Yin, J., Hu, L., et al. (2020) Effect of Hydrogen Peroxide Bleaching on Anionic Groups and Structures of Sulfonated Chemo-Mechanical Pulp Fibers. Colloids and Surfaces A: Physicochemical and Engineering Aspects, 585, Article ID: 124068. 
https://doi.org/10.1016/j.colsurfa.2019.124068

[28] Siminiuc, R. (2020) The Influence of Biotechnological Strategies on Nutritional Aspects of Bakery Products.

[29] Goupy, J. and Creighton, W.L. (2007) Introduction to Design of Experiments with JMP Examples. 3rd Edition, SAS Institute, Cary.

[30] Azer, S.S., Hague, A.L. and Johnston, W.M. (2011) Effect of Bleaching on Tooth Discolouration from Food Colourant in Vitro. Journal of Dentistry, 39, e52-e56. https://doi.org/10.1016/j.jdent.2011.09.006

[31] Posoknistakul, P., Akiyama, T., Yokoyama, T. and Matsumoto, Y. (2017) Predominant Formation of Aromatic Aldehyde and Acid from a Dimeric $\beta$-O-4-Type Lignin Model Compound under Hydrogen Peroxide Bleaching Conditions with High $\mathrm{pH}$ Levels. Journal of Wood Science, 63, 173-182. https://doi.org/10.1007/s10086-017-1609-4

[32] Miglbauer, E., Gryszel, M. and Głowacki, E.D. (2020) Photochemical Evolution of Hydrogen Peroxide on Lignins. Green Chemistry, 22, 673-677. https://doi.org/10.1039/C9GC04324A

[33] Khaliq, A.D., Chafidz, A., Maddun, F.R., et al. (2019) The Use of Hydrogen Peroxide and Sky Stabilizer Agent in Bleaching Process of Textile Fabrics. AIP Conference Proceedings, 2138, Article ID: 050011. https://doi.org/10.1063/1.5121116

[34] Wang, N., Tang, P., Zhao, C., et al. (2020) An Environmentally Friendly Bleaching Process for Cotton Fabrics: Mechanism and Application of $\mathrm{UV} / \mathrm{H}_{2} \mathrm{O}_{2}$ System. Cellulose, 27, 1071-1083. https://doi.org/10.1007/s10570-019-02812-3

[35] Eskandari, M., Rembiesa, J., Startaite, L., et al. (2019) Polyphenol-Hydrogen Peroxide Reactions in Skin: In Vitro Model Relevant to Study ROS Reactions at Inflammation. Analytica Chimica Acta, 1075, 91-97.

https://doi.org/10.1016/j.aca.2019.05.032 